\title{
MENTAL HEALTH IN RELATION TO THE LABOUR TURNOVER OF UNSKILLED WORKERS IN A LARGE INDUSTRIAL ESTABLISHMENT
}

\author{
BY \\ MORRIS MARKOWE and LESLIE E. D. BARBER \\ From the Unit for Research in Occupational Adaptation, Medical Research Council
}

Study of the relationship between mental health, psychological handicap, and industrial conditions has developed considerably in importance during the last 5 years. Wartime investigations connected with the occupational adaptation of discharged service men were described by Lewis and Slater (1942), Lewis (1943), and Guttman and Thomas (1944), and the findings of Fraser (1947) on the incidence of neurosis in factory populations and its association with absenteeism are well known. The effects of such disability on working efficiency are by no means clear. Studies in factories (Markowe and Barber, 1952; 1953) have not confirmed the widely held notion that individuals who have a neurotic. handicap often produce less than the average worker, though they showed that those with poor intelligence tended to have a lower output.

It has frequently been asserted that neurotic workers are more prone to change their job than those enjoying normal mental health. Reasons for leaving employment may, however, be social and economic as well as psychological (Long, 1951). In the present inquiry an attempt is made to relate labour turnover to mental health, by examining the association between length of stay in a new job and the incidence of neurotic disability. The study is based on unskilled workers in two large factories; men and women are considered separately.

\section{MATERIAL}

MEN.-This part of the study was carried out in an extensive medium and heavy engineering factory on the fringe of Manchester. Preliminary meetings were held with management, foremen, and shop stewards in order to explain the purpose of the study and obtain their cooperation and assistance; it would otherwise have been impossible to approach individual workers directly and ask them to take part in the investigation. An industrial dispute between the Engineering Union and employers in the North West Region delayed the project by some months, since the normal pattern of entry and exit in the industry was thereby affected. The attitude of industrial workers to the study would also have been suspicious or hostile at that time.

A random sample was taken, consisting of 100 unskilled male workers accepted for employment at the factory between March and November, 1951. The sample was selected by using tables of random numbers on the weekly lists of "starters" supplied by the labour office. The selection was in no way related to the department or actual job to which workers were assigned. Two men refused to be interviewed; they were replaced in the sample.

The workers were assigned to unskilled tasks in different departments; these included automatic machine tending, non-automatic machine tending, inspection, manual labour, and work on electrochemical processes or special constructions. Excluded were workers below the age of 23 (and therefore still liable to national service), and foreigners who might have found language difficulties in the tests.

WOMEN.-This part of the enquiry was carried out in a large light engineering factory, also on the fringe of Manchester, employing mainly female labour. Fresh workers were constantly needed and therefore an adequate sample was readily obtained. Because of the tradition of workers' welfare in the firm, the women were ready to co-operate, and the research had the initial approval of the management and shop stewards.

A random sample was taken, consisting of 100 unskilled female workers accepted for employment at the factory between March and November 1951. The workers were engaged in the machining or assembly of small components and the sorting, grading, and packing of small parts. Such work generally demands finger dexterity and patience, but rarely strenuous exertion; facility in it could usually be achieved after a short training.

\section{MeTHods}

Each worker was interviewed clinically during the first week of employment. Height, weight, visual acuity, and haemoglobin were measured. A medical questionnaire followed, and then a test of general mental ability. Special tests of blood pressure, ischaemic endurance (described below), and exercise tolerance (Behnke) were 
administered. Each individual's life history, health, and occupational record were ascertained, and his psychological handicaps of personality assessed at the time of the interview and during the previous 12 months. He was then rated on five-point scales for mental health and personality traits.

Recent mental health ranged from Rating 1 (healthy, mature, vigorous, and well-integrated) to Rating 5 (definite disabling sickness, mainly of moderate severity, requiring treatment). Ratings 2 and 3 covered the rest of the "normal" range; Rating 4 included minor states of ill-health which, although they did not materially incapacitate the individual or oblige him to seek treatment, interfered with his domestic, social or working life. Those with Ratings 1,2 and 3 were considered to be "normal". Those with Ratings 4 and 5 were considered to be "psychologically handicapped"; they were neurotic or emotionally unstable.

The personality traits assessed were Resolution, Affective Lability (emotional instability), Extraversion, Emotional Maturity, Obsessionality, and Conscientiousness; they were operationally defined.

In addition to clinical assessment of intelligence or dullness, a pure test of general mental ability (the Dominoes Test) was administered under standard conditions. This is a non-verbal test, consisting of 48 items, which has been well standardized and validated on large groups of national service men taken into the Army.

Finally, blood pressure estimation was followed by inflation of the cuff to a pressure of $250 \mathrm{~mm}$. $\mathrm{Hg}$., while the subject was instructed to clench and open his fist at the rate of once per second for as long as he could bear it, or up to 5 minutes. In this ischaemic state responses ranged from no discomfort to acute distress; the majority experienced much discomfort. The length of time in seconds was the score of "endurance".

The occupational record obtained during the interview included data about the duration of each past job and reasons for leaving it.

Each subject was "followed up" for a period of 6 months. The nature of his or her work was ascertained, as well as his adjustment to it, his absences, and whether he left during this period. "Leavers" were defined as those who left within 6 months of being taken on. During the period of the study no one was dismissed. Comments were obtained from the subjects' immediate supervisors about their attitude to the job.

Certain general considerations restricted the clinical interview. First, absence from work lowered the subject's earnings, as this period was not covered by payment on the firm's basic rates. Secondly, if (as was usual) the worker felt "healthy", he failed to see the need for the physical examination, tests, and survey of his history, so that the tests and physical appraisal had to be brief.

\section{RESULTS}

SAMPLES

Men.-Ages ranged from 20 to 62 , with a mean of $39 \cdot 35$ (standard deviation $11 \cdot 3$ ); there were nearly as many over 45 as under ( 25 were between 20 and 29; 33 were between 30 and 44 ; and 42 were 45 or over). Of the 100 men, 78 were married, and only sixteen of these had no children.

Normal mental health was found in 57 of whom 41 were entirely free from symptoms; 43 were psychologically handicapped, nine being moderately and 34 mildly affected (see Table I). Their handicaps included anxiety states, depressive states, emotional instability, dullness, and feeble-mindedness. Nevertheless only a few of these 43 men were under medical treatment.

Intelligence scores as measured by the Dominoes Test ranged from 5 to 35 points (maximum possible was 48 ), with a mean of 22.71 and standard deviation of $6 \cdot 93$. This corresponds to a mean IQ of 91 ; this equivalence is not derived from direct standardization and must therefore be considered approximate.

Women.-The women formed a cross-section of the working community during a year of full employment. They were heterogeneous in most respects, yet uniform in the desire to earn, often in order to augment their family budget.

Ages ranged from 15 to 58 , with a mean of 32.82 (standard deviation $10 \cdot 29$ ), with a majority below 45 ( 38 were between 15 and 29,47 between 30 and 44 , and 15 were 45 or over). Of the 100 women, 73 were married, and only sixteen of these had no children.

Normal mental health was found in 45 , of whom only 21 were entirely free from symptoms; 55 were psychologically handicapped, of whom nineteen were moderately and 36 mildly affected (see Table I). The handicaps included anxiety states with and without somatic symptoms, hypochondriasis, oversensitive and suspicious traits, emotional instability, and inadequate personalities. The married women showed a higher incidence of psychological ill-health than the single.

Intelligence scores on the Dominoes Test ranged from 7 to 36 points, with a mean of 21 (standard deviation 6.43 ), corresponding to an IQ of 89 (see above under Men).

Socio-Medical Factors in Relation to Leaving

Within 6 months of having been taken on, 21 men and 52 women had left work.

Health ratings, personality traits, and biographical data were tabulated against leaving, and in some cases against psychological handicap. Standard tests of significance showed few statistically significant associations. Thus a clear association was found in the men between leaving and psychological handicap, past employment record, affective lability, 
and parental deprivation, and in the women between leaving and past employment record, certain personality traits, and performance on the ischaemia test. The remaining comparisons, though not significant at the conventional level did not indicate complete lack of association. Owing to the impossibility of controlling independent variables in the social occupational field, the attenuation of association is to be expected. In these circumstances probability levels between 0.05 and 0.2 may not be arbitrarily dismissed.

\section{Psychological Handicap}

Men.-Fourteen of 21 men who left were psychologically handicapped, as compared with 29 of 79 who stayed. It would, however, be unsafe to attribute a great deal to this difference, since only two of the fourteen who left were moderately handicapped, while of the 79 seven were moderately neurotic. Nevertheless the difference is significant $\left(\chi^{2}=6.07, \quad P<0.02>0.01\right)$. Twelve of the 34 mildly handicapped men left, and 22 stayed.

Women.-32 of 52 women who left were psychologically handicapped, as compared with 23 of 48 who stayed $\left(\chi^{2}=1 \cdot 87, P<2>0 \cdot 1\right)$. Although the difference is not significant, it is in the same direction as in the male group. Fourteen of the nineteen moderately handicapped women left, as against five who stayed. Eighteen of the 36 mildly handicapped left and eighteen stayed.

\section{Personality Traits}

Men.-Those with "affective lability" showed a significant association with leaving $\left(\chi^{2}=5 \cdot 69\right.$, $P<0.05,>0.02)$. Men with stable temperament and steady emotional state, whether phlegmatic or pessimistic, tended to stay on the job.

Women.-Conscientiousness and obsessionality were both found to be significantly related to staying on the job $\left(\chi^{2}=5.69, P<0.02,>0.01\right.$ for conscientiousness; $\chi^{2}=3.93, P<0.05,>0.02$, for obsessionality). Among the women, the extraverts showed a greater tendency to leave.

There was no association between leaving and either maturity or resolution in the men or women.

IsChAEMIa TEST OF ENDURANCE.-The time of endurance in seconds of obliterative ischaemia of the right upper arm was noted and the means calculated for those who left and for those who stayed.

Men.-Those who left had a mean score of $184 \cdot 7$ seconds, as compared with $198 \cdot 59$ seconds for those who stayed. Standard error of the difference $19 \cdot 216$.
Women.-Those who left had a mean score of 146 (standard deviation 4.79), and those who stayed a mean score of 175 (standard deviation 80.64). Standard error of the difference $11 \cdot 66$. It should be noted that the variation about the mean, while small in the case of those who left (indicating a relatively compact group) is considerable for those who did not leave (possibly due to the many reaching an arbitrary maximum score of $300 \mathrm{sec}$.).

AGE.-There was no significant relationship between age and leaving, although in the men there were more psychologically handicapped in the younger age group. In the women there was no significant relationship between age and psychological handicap; more of the younger women tended to leave, but the trend was not significant.

Mental ABILITY.-There was no association between leaving and mental ability, either in the men or in the women.

\section{Marital Status}

Men.-The married workers compared with single were fourteen to seven in the leavers, and sixty-four to fifteen in the non-leavers; thus the married appeared to be less disposed to leave, but the difference is not statistically significant. The married with children exceeded the childless to a greater degree among leavers than among nonleavers, but the difference is not significant.

Women.-Of those who left, 42 were married as compared with ten single; of those who stayed, 31 were married and seventeen single. The difference is not significant $\left(X^{2}=3.33, P<0.05,>0.1\right)$.

Past Changes of Employment.-The changes in employment under consideration in this paper cover the years 1945-51, a period of full employment coupled with the partial removal of the Essential Works Order. This period was chosen in order to secure:

(i) a defined period sufficiently short for reliable statements and recollections,

(ii) a period within which earnings and opportunities of employment were stable and comparable.

The period of sampling for this study escaped the subsequent recession and redeployment in the textile industry - an unexpected development which would have affected the turnover of labour, and the proportions of normal and handicapped individuals in the samples.

Men.-A comparison between those with a history of one to three changes of job in this period and those with a history of four or more jobs, 
showed that the psychologically handicapped had been through more jobs than had the normal group $\left(\chi^{2}=4.949, P<0.05,>0.02\right)$. As far as the present group of leavers was concerned, seven of the 21 had a history of four or more changes of job in the period 1945 to 1951 .

Women.-Those with six and more job changes included thirteen handicapped and four normal; those who had had not more than five jobs included 42 handicapped and 41 normal. $\left(\chi^{2}=3 \cdot 81\right.$, $P=0 \cdot 05$ ). As far as the present group of leavers was concerned, ten of the 52 had a history of six or more changes of job in the period 1945-51, and thirty of the 52 had had four or more changes.

These findings support the assumption that persons with psychological handicaps tend to change their jobs more often than do those in the normal range.

\section{Parental Deprivation}

Men.-Absence of one or both parents during childhood, before the worker had left school, whether due to death, desertion, or divorce, was found to be associated with leaving $\left(\chi^{2}=4 \cdot 627\right.$, $P<0.05,>0.02$ ). Out of the total sample of 100 , 37 were found to have been so deprived; this is a considerable proportion in any socio-economic group.

Women.-The corresponding number was thirty, and was not significantly associated with leaving.

\section{INDUSTRIAL FACTORS IN RELATION TO LEAVING}

Men.-There was no significant relationship between leaving and the size of the labour force in each department, or the nature of the work. Within the labouring group of sixty, however, the handicapped were in a majority among the leavers (nine out of twelve), $\left(\chi^{2}=6.817, P<0.01\right.$, $>0.001)$.

Women.-There was no significant relationship between leaving and the size of the labour force in each department, the nature of the work, predominance of women over men, or wholly female staffing. Nor was there a significant relation between any of these factors and psychological handicap.

\section{LeNGTh of Stay}

Men.-Those who left in the first 10 weeks were normal or handicapped in equal numbers, whereas those who left between 11 and 26 weeks after starting were all handicapped. On the average, the handicapped left after 10.4 weeks, as compared with
$4 \cdot 7$ weeks for the normals who left (' $t$ ' is significant at 0.05 level).

Women.-The handicapped appeared to leave either early in their occupational encounter or after many weeks; the normal appeared to leave early or to stay for more than 6 months. On the average, the handicapped left after 11 weeks, as compared with 10 weeks for the normals who left. As the distribution was not normal, ' $t$ ' test was not applicable. $\left(\chi^{2}=0.98, P>0 \cdot 3\right)$.

\section{Discussion}

The high incidence of neurosis in the samples is striking, particularly in the female group (Table I, opposite).

The figures are higher than those observed by Fraser (1947) in a comparable population, though is if the non-leavers alone are considered, the disparity is less (Table II, opposite). Many of the early leavers may have eliminated themselves from his population, although they were subject to the Essential Works Order. It is hardly likely that the disparity arises through different criteria of neurosis, since in earlier studies in the light engineering industries we have found figures for the prevalence of neurosis very close to his.

The lesser frequency of leaving among mem 21 per cent.) than among women (52 per cent. indicates a sex difference in occupational behaviour. This phenomenon is well known: thus, for the period March to November, 1951, the electrical machinery industry had a national labour turnover of approximately 16 per cent. for males and 21 per cent. for females (Ministry of Labour Gazette, 1952).

It is not easy to see why men with more severe neurotic disorder tended to stay in their jobs, while those who left were either healthy or had only minor neurotic complaints. Neurotic persons are generally expected to show signs of maladjustment, if at all, soon after entry into a new field of work; experience in the armed services during the war was in conformity with this. But in civil life the anxious neurotic imperils his precarious feeling of security, it may be supposed, if he leaves a newly acquired employment. For women, however, this can be only one factor, as fourteen of the nineteen severely handicapped left within 6 months, and the more severe their neurosis, the sooner they tended to leave.

There was a tendency for marriage to be associated, in the women, with leaving. This may be accounted for by the additional stresses experience by married women when employed in factories. The domestic needs of husband and home, problems of the family 
TABLE I

GENERAL DISTRIBUTION OF GROUPS BY MENTAL HEALTH RATINGS AND CONTINUANCE IN EMPLOYMENT

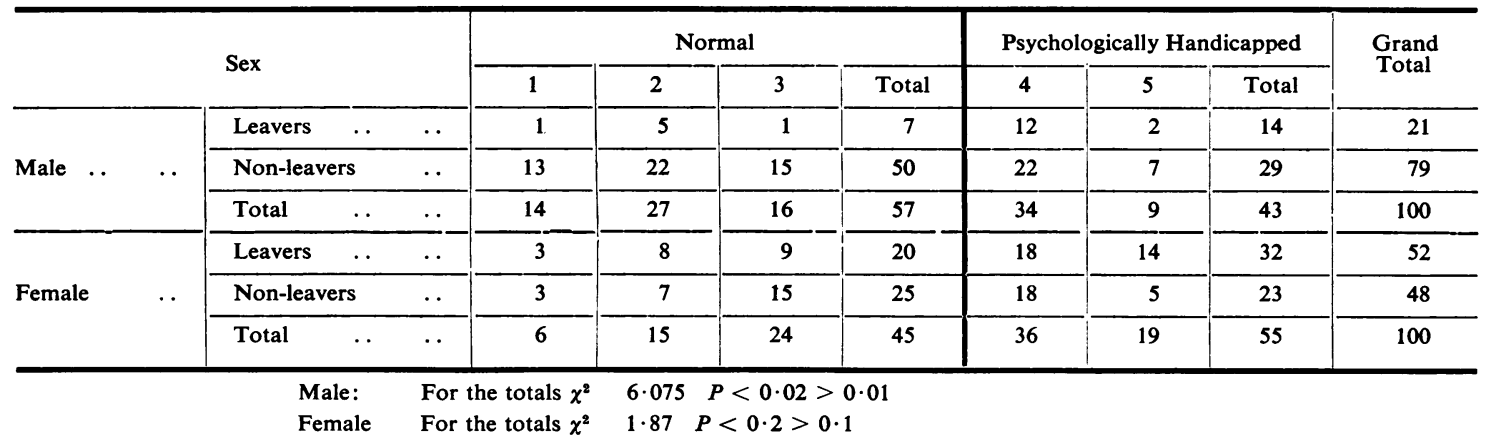

TABLE II

PERCENTAGE INCIDENCE OF NEUROSIS COMPARED WITH RESULTS OF PREVIOUS INVESTIGATIONS

\begin{tabular}{|c|c|c|c|c|}
\hline \multirow{2}{*}{ Author } & \multirow{2}{*}{ Date } & \multirow{2}{*}{ Sex } & \multicolumn{2}{|c|}{ Degree of Neurosis } \\
\hline & & & Mild & Definite \\
\hline \multirow{2}{*}{ Fraser } & \multirow{2}{*}{1947} & Male & $19 \cdot 7$ & $8 \cdot 5$ \\
\hline & & Female & $37 \cdot 5$ & $10 \cdot 4$ \\
\hline \multirow{2}{*}{$\begin{array}{c}\text { Markowe } \\
\text { and } \\
\text { Barber }\end{array}$} & \multirow{2}{*}{1953} & Male & 34 & 9 \\
\hline & & Female & 36 & 19 \\
\hline
\end{tabular}

budget, and concern over the care of children, by neighbours or in nurseries, all add to the psychological and physical demands of work in the factory. Many of the married women declared that they were not fatigued by the job but were exhausted at the end of the day after also completing their domestic chores.

It was not surprising that general mental ability showed no relationship to leaving. The types of unskilled work in question do not call for much intelligence. Many dullards and high-grade defectives are accepted by employers as adequate for such work, and various studies have demonstrated that they can adjust satisfactorily (Tizard and O'Connor, 1952).

One of the most significant differences between women leavers and non-leavers was found in the ischaemia test of endurance. While the ability to continue muscular activity in spite of painful discomfort must be affected by physiological as well as psychological factors, in this experiment the varying performance of the women may be assumed to reflect, under conditions of equal motivation, qualities of persistence and determination in the face of difficulty. Such qualities could be highly relevant to the question whether a worker will continue at his employment, whatever the adverse forces. The findings in the men, however, speak against this suggestion; they showed no clear difference between leavers and non-leavers in the endurance of pain in the ischaemic test. The matter calls for fuller study.

Occupational records of both men and women showed that those with neurotic handicaps had changed their employment in the past more frequently than the remainder, although the Association is not however confirmed in this study of 6 month's employment of women workers.

The jobs to which workers are allotted broadly depand upon the demand for labour from departments and in the case of the women upon the empirical recommendations of the training school through which most of them pass. When there is a greater demand for some product, e.g. radio sets for the open market or products for the defence programme, the department concerned becomes more willing to carry workers with a psychological handicap such as abnormal anxiety, irritability, or depression.

These findings were obtained in two large factories of a single company in an extensive industrial area. Factories with not less than 250 workers (those here studied each employ 2,000) comprise, in fact, only some 10 per cent. of manufacturing firms, and cover a third of such employment. Therefore, while this study is conclusive in some directions for large employers, it would be unsafe to assume that the present conclusions would be applicable to the wide range of smaller establishments.

\section{SUMmary}

(1) A random group of 100 men was selected from newly engaged unskilled workers accepted for employment at an engineering factory between March and November, 1951. A similar group of 100 women was selected from workers accepted for 
employment at a branch factory in the same district during the same period.

(2) Each subject was interviewed clinically in the first week of employment and rated on 5-point scales for mental health and personality traits; tests of mental ability and ischaemic endurance were given, and data obtained about past employment. Each subject was "followed up" for 6 months, and his continuance in the job related to these data. Twenty-one of the men, and 52 of the women left within 6 months of starting the job.

(3) Forty-three of the men and 55 of the women had neurotic symptoms. Of the 21 men who left, fourteen had neurotic symptoms. Of the 52 women who left, 32 had neurotic symptoms.

(4) Seven of the 21 men and thirty of the 52 women had a history of four or more changes of job between 1945 and 1951.

(5) Neurotic men who left did so, on the average, after 10 weeks, compared with 4 weeks for the mentally healthy. There was no significant difference between the non-neurotic and neurotic women in this respect. The more severe the neurotic disability of men who left, the longer they stayed before leaving. Among women the more neurotic left earlier.

6) No association was found between leaving and (a) general intelligence (both sexes);

(b) age (men).

(7) Scores of the ischaemia test of endurance were different for women who left and for women who stayed.

(8) Although no association was found between leaving and size of department or type of work, there was a highly significant relation between handicap and leaving in the "labouring" group of sixty men.

Acknowledgments for both studies are made to Professor Aubrey Lewis, Honorary Director of the Unit, for guidance and criticism throughout, to Dr. V. Norris for statistical advice, to our colleague Dr. P. Venables for invaluable assistance in the compilation of the data, and to the Management and Personnel Department of the factories concerned for their lively co-operation.

\section{REFERENCES}

Fraser, R. (1947). "The Incidence of Neurosis Among Factory Workers". Rep. industr. Hith Res. Board., (No. 90) Lond.

Guttman, E., and Thomas, E. L. (1946). "A Report on the Re-adjustment in Civil Life of Soldiers Discharged from the Army on Account ment in Civ". Report No. 93 Min of Health. H. S.O. London. Lewis, A. J. (1943). Lancet, 1, 167.

and Slater, E. (1942). Ibid, 1, 496.

Long, J. R. (1951). "Labour Turnover Under Full Employment", Studies in Economics and Society, Monograph A2. University of Birmingham.

Markowe, M., and Barber, L. E. D. (1952). Brit. J. industr. Med., 9 , 221.

Mind and (1953). Ibid., 10, 125

Ministry of Labour Gazette (1952). 60, 286.

Tizard, J., and O'Connor, N. (1952). Lancet, 2, 620. 